\title{
The Impact of User-Generated Content on Digital Transformation of Tourism and Travel Services: Evidence from the Egyptian Travel Agencies
}

\author{
Mahmoud A. Aboushouk ${ }^{1}$ \\ Tamer M. Elsawy \\ Faculty of Tourism \& Hotel Management, Pharos University in Alexandria (PUA)
}

\begin{abstract}
The continuous development of information technology has fundamentally revolutionized our communication patterns and behavior through the Internet, establishing a digital medium in which information is consumed and disseminated. In this context, most tourism researches focus on the role of UGC in directing the decision of visitors in determining the tourist destination that could be visited or the service provider that could be selected.

This research aimed at measuring the impact of user-generated content on the digital transformation of Egyptian travel agencies as well as investigating how UGC can stimulate the digital transformation of tourism and travel services.

For this purpose, the researchers used the deductive approach and quantitative method. Semistructured questionnaires were distributed to a sample of 278 managers out of 1008 travel agencies, in addition to a sample of internet users including social media users, using a simple random sampling technique.

Moreover, researchers analyzed the literature regarding the fast-paced e-commerce environment to understand the complicated behaviour of consumer which shows that consumers are rapidly changing and that is what they also expect from the mediums they are dealing with. Findings of the study have indicated that User-generated content has a weak positive effect on the digital transformation of Egyptian travel agencies.

Implications for practice were suggested to support the digital transformation of Egyptian travel agencies based on user-generated content.
\end{abstract}

Keywords: User Generated Content (UGC), Digital Transformation (DT), Travel Agencies, Tourism and Travel Services.

\section{Introduction}

According to (Internet World Stats, 2019), more than 4.3 billion are Internet users (56.1\% of world's population in March 2019) where Asia and Europe, which are the major tourist market for Egypt, are the predominant regions in terms of Internet usage with a share of $67 \%$ of Internet users worldwide.

The Internet has dramatically altered the behavior of tourists. Tourists of today have direct access to a great wealth of information and can handle their online purchases themselves rather than relying on travel agencies (C. Hidalgo Alcázar, et al., 2014).

Hence, in the digital era, travelers have more choices and are better informed. Today's Travelers have different expectations and want the information relevant to their needs to be easily accessible in a matter of seconds, as they have little tolerance for websites that do not present the needed information immediately (Mari Jansen Rensburg, 2014).

Moreover, (Shivani Arora, 2019) added That, the complicated behavior of consumers on one hand are rapidly changing also they expect from the mediums they are dealing with, on the other hand, where rapid changes happened in terms of medium from 'brick and mortar' to 'online'; from websites to apps, and from laptops to smart phones starting from the launch of the iPhone in

\footnotetext{
${ }^{1}$ Corresponding author, Mahmoud Aboushouk, Pharos University in Alexandria, Dr.mahmoudahmed@pua.edu.eg
} 
2007, followed by the deployment of Google's Android devices in the mass market (Ribeiro R. \& Florentino T., 2016). Therefore Tourism was one of the first industries to digitize business processes.

Additionally, tourism industry has always depended strongly on automation to provide its services. Early attempts to automate flight reservations started with American Airlines' reservoirs, which was replaced by the Sabre system developed by IBM in 1960. This platform is still alive as one of the major global distribution systems (GDS) used by travel agencies to book air, hotel, and car for customers, as well as its rivals such as Amadeus and Galileo (IATA, 2017). Also, tourism become a digital pioneer bringing online flight and hotel bookings (UNWTO, 2019).

Furthermore, according to (UNWTO, 2019 \& World Economic Forum, 2017) technologies such as the Internet of Things, location-based services, artificial intelligence, virtual and augmented reality, and block chain technology has led in a more appealing, effective, inclusive and economically, socially and environmentally sustainable tourism sector than its predecessor.

As a result travel services providers shifted from data management and processing within the business's IT department, as well as administrative and support functions to key business processes as designing new products and services (Gimpel, H. \& Röglinger, M., 2015) so they gained better understanding for their customers, convincing them to stay loyal and make repeat purchases (Shivani Arora, 2019).

The challenge according to (Rui Ribeiro, 2019) is not how to get or generate data, but how to use it and transform it into something that has a business focus and value.

This potential to transform data in real-time mode into wisdom is pushing businesses to transform themselves, which is simply known as Digital Transformation, but what is happening is that they are transforming their own value chain.

A study by Anna Kreider, (2018) concluded that whereas businesses are aware of the importance of digital transformation; they do not act on that understanding. Also, she found that while $84 \%$ of businesses believe that digital transformation is crucial, and $78 \%$ of executives consider digital start-ups as a threat, only $3 \%$ have acted according to that.

Moreover, according to (The World Bank, 2018) tourism businesses in developing destinations have limited knowledge on how to take advantage of digital platforms and mitigate risks to develop their business, either restricted by the lack of understanding or know-how and resources. Consequently, according to Ribeiro R. \& Florentino T., (2016) some of the stakeholders in the value chain will be pushed away out of the market if they did not have the time to adapt.

Based on the fore mentioned this research problem is summarized in the following two questions:

- Do the Egyptian travel agencies use and transform user generated content into something that has a business focus and value?

- Do the Egyptian travel agencies adapt themselves, to Digital Transformation?

This research objectives are: (1) Measuring the effect of User generated content (UGC) on the digital transformation of Egyptian travel agencies (DT); (2) Measuring the effect of User generated content (UGC) on the customers' intention to purchase (IP); (3) Measuring the effect of the customers' intention to purchase (IP) on the digital transformation of Egyptian travel agencies (DT); (4) Measuring the correlation between user generated content and intention to purchase. 
This research proposes models depicts a renewed version of the previously proposed models that better explains user generated content, intention to purchase and digital transformation of the Egyptian travel agencies.

Moreover, it provides valuable recommendations and implications for the Egyptian travel agencies to get benefit of user generated contents and adapt to digital transformation.

\section{Literature review:}

\section{User-generated content (UGC)}

Recent studies by (Chevalier and Mayzlin, 2006; Duan et al., 2008; Ghose and Ipeirotis, 2011; Hazari et al., 2016) has explored UGC related topics such as customer engagement, e-word of mouth, online brand reputation management, customer relationship management, trust, purchase intention, and social network analysis.

According to Irina Albăstroiu \& Mihai Felea (2014), the terms User-Generated Content (UGC) or Consumer-Generated Media (CGM) are widely used to illustrate the key role individual customers play in submitting, reviewing and reacting to online content. In tourism context, some researchers prefer to call it Tourist Created Content (TCC) (Ana María Munar, 2010).

Moreover, Irina Albăstroiu \& Mihai Felea (2014), argued that UGC is related to the digital transformation of objects: texts, sounds and images.

UGC defined by (Blackshaw \& Nazzaro, 2006; Akehurst, 2009; KhairulHilmi Manap \& Nor Adzharudin, 2013) as the online reviews, profiles and photos generated by customers, especially travelers, and is also a combination of facts and opinions, impressions and feelings, founded and unfounded tidbits, experiences and even rumors.

A lot of websites nowadays enable customers to add their own content through general text comments, travel reviews, images, and video (Ahuja et al., 2007).

Fernando (2007), indicates that UGC is the reverse of traditional media and marketing since the content is produced by the customer rather than the marketer. While using social networks the power of the user is growing, influencing their friends or unknowns.

These actions generate a large volume of unstructured information that companies should ideally analyze in real-time mode.

The analysis of this large amount of data will be a difficult but important task especially for small and medium-sized travel agencies and other tourism stakeholders to maintain or become competitive. These data will help them to understand what are the needs and experiences that the potential customers are looking for and adapting their business to those fits.

(Sparks, B. et al., 2013) added that tourist businesses will be able to understand the trends of the market in real time, also will know what customers are saying about them. This is a crucial issue because tourists believe more in the comments and opinions from their peers (known or unknown) than in any business organization's official websites or even magazines articles.

In this manner, (K.-H. Yoo and U. Gretzel, 2011; S. Molinillo et al., 2016) stated that, the customer (tourist) is playing a double role because he/she can be information consumer on one hand and opinion/information supplier through eWOM on the other.

This can be illustrated over several websites of Online Travel Agencies (OTA), such as Expedia.com, Booking.com and TripAdvisor.com.

This study adopted the definition of (Sethna, B.N., et al, 2017), about UGC as "reviews and opinions posted online by other users for a tourism product/service which can include comments, criticism, or self-experience reflecting the product/service features, design, utility, packaging or delivery". 


\section{Intention to purchase}

A shift from traditional e-commerce to a new type of framework has taken place, often referred to as social commerce. Blog posts and online comments are a component of social commerce that can be used to influence attitudes, decision-making, and intention to purchase (Sethna, B.N., et al, 2017).

UGC becomes a significant element in the purchase decision process as it contains an object (i.e., brand), topic (i.e. Customer) and valence (positive or negative) (Hollebeek L. and Chen T., 2014; Dessart L. et al., 2015). Sethna, B.N., et al., (2017) stated that UGCs have a high impact on brand's reputation and purchasing intentions. According to the World Intellectual Property Report (2013), a brand's reputation and image affect the earnings of the business, the intention of customers to purchase and the outcome of their marketing, all of which will subsequently have a long-term effect on their sustainability (Hussam Al Halbusi \& Shehnaz Tehseen, 2018).

Social media platforms such as Facebook, Instagram and Twitter which allow users to easily share photos or recommendations are extremely influential tools especially when it comes to the intention to purchase. About $92 \%$ of users rely on this particular information if they are friends or family.

In a study on these opinions, 52\% of Facebook users said that the photos of the friends had inspired the choice of their holiday, $38 \%$ of people use their smart-phone and its social networks to get recommendations while travelling and more than $50 \%$ use social media to plan a trip (Ribeiro R. \& Florentino T., 2016). Park et al. (2007) concluded that consumer purchasing intentions increased in line with the number of reviews indicating the popularity and quality of the product or service.

\section{Digital transformation (DT) of tourism and travel services}

ICT developments along with altering customer behaviors and the emergence of new players in the travel industry added complexity to the travel distribution system (Kracht \& Wang, 2009). These changes will not affect only the choices made by the customer, but business models and adopted marketing strategies as well (Julia Nevmerzhitskaya, 2013).

For the sharing of information, the business model nowadays is shifting from business-tocustomer marketing to a peer-to-peer model. Thus, all tourism businesses are urged to adopt tools and strategies based on user-generated contents or, at least, to incorporate this new model to enhance its competitive advantage (Irina Albăstroiu \& Mihai Felea, 2014).

Gartner predicts that $75 \%$ of businesses will be digital or will be prepared to become digital by 2020 (Mohammed H., 2016). Digital transformation impact will shape how tourism business engages and communicates with its customers (KhairulHilmi Manap \& Nor Adzharudin, 2013).

According to Hans Gelter, (2017) the digital transformation of business is not just about being on the Internet. The use of smarter digital document flows, e-accounting, mobile payments, and cloud storage is crucial, particularly for micro and small businesses.

Digitalization is a process, not an overnight occurrence. It offers the tools, frameworks and techniques for creating and/or adding value to tourism products and experiences, but digitalization success depends on the tourism sector's ability to share, learn and cooperate (Dredge, D., et al., 2018).

In the literature, there are multiple perceptions of digital transformation. The idea of a digital transformation stems from the mixing of personal and corporate IT environments and encapsulates the transformative effect of new digital technologies such as social, mobile, analytics, cloud and the Internet of Things (SMACIT) (Kane et al. 2015; Mariam H. Ismail et al., 2017; Sebastian et al. 2017). 
A general definition defines (DT) as the integration of digital technologies and business processes in a digital economy (Mariam H. Ismail et al., 2017). A more comprehensive perception sees digital transformation as the use of these technologies to impact three organizational dimensions:

(1)externally, focusing on digitally enhancing customer experience and shifting the entire life cycle of the business; (2)internally, affecting business operations, decision-making and organizational structures; and (3)holistically, where all business segments and functions are influenced, this often leads to completely new business models (Kaufman \& Horton 2015; Schuchmann \& Seufert 2015; Mariam H. Ismail et al., 2017).

The development of technologies such as big data and cloud computing has made it much easier to customize packages and products based on user preferences. Travel businesses can achieve personalization through the deployment of big data that helps provide insights into the minds of travelers including favorite destinations, preferences of airlines and much more.

Consumers today have more tools than ever before to wield their influence and opinion, but customer-generated content becomes a double-edged sword for businesses.

In review sites which based on user-generated comments, travelers speak directly to the company and its staff. The business that will be ready and keen to listen is the one that will be able to flourish.

It can take years and millions of dollars to build brand image and reputation, which should be the most important task for any business. Therefore, businesses should not let even one online negative review or comment unnoticeable (Ozlem Alikilic, 2018).

Utilizing the power of technology and the Internet, travel agencies can turn their customers into their own employees. By Digital Transformation of their services, customers can make their online bookings, printing the vouchers and obtaining all the required information, photographs about places, hotels, restaurants and gaining access to the world; this system offers advantages at a low-cost advantage to the businesses (Ozlem Alikilic, 2018).

Digital Transformation of Tourism and Travel Services can take various forms and levels. For instance, Travel agencies can Combine information from specialists in the travel industry with real feedback from actual travelers or by creating an area on their website that allows travelers to interact with each other at all steps of their holiday planning by posting, reviewing and sharing pictures and video content (Irina Albăstroiu \& Mihai Felea, 2014).

QR codes are another excellent way to add a web call to action to explorer or print promotional and interpretation media such as brochures or flyers (Irina Albăstroiu \& Mihai Felea, 2014).

The major challenge to achieve positive cash flows in a business is the ability to provide a business model capable of engaging customers with a new service development (NSD). Therefore, to achieve this one-to-one engagement, the change in business models begins with the maturity of Web2.0 and the first implementation projects of Web3.0 along with Internet of Things (IoT), (M. Sigala, et al., 2012). The transformation from the Web2.0 to Web3.0 introduces new challenges, implying that we are changing for the Semantic Web concept, which means that search engines and software agents can better understand what the users are looking for or need. Thus, the importance of the adoption of this change is essential (Ribeiro R. \& Florentino T., 2016), especially when it comes to a dynamic and widely ramified industry such as tourism. Mari Jansen Rensburg, (2014) stated that to use this platform to achieve economies of scale and rationalize costs, awareness of its functionality and resources is required.

The most lucrative businesses are who providing a fresh set of value-added services, such as the relationship experience with their clients, which gives them closeness, quick responses, solving 
short-term questions, in addition to the current traditional services (Ribeiro R. \& Florentino T., 2016). S. Molinillo, et al, 2016 stated that many visitors no longer prefer to use the services of traditional travel agencies, but instead, search and plan their travel through specialized websites, where the admin of these pages must be aware of what is said and proactively convince prospective customers, meaning that they start to create a "digital customer intimacy". Therefore, over the years, online travel agents (OTA) have grown stronger. OTA are online businesses whose apps/websites facilitate the customers in booking different travel-related services directly via the Internet (Shivani Arora, 2019).

Value-added provided by travel agencies must also be adapted to satisfy the evolving customer purchasing habits of tourism products. The issue here, travel agencies must give their customers good reasons for visiting their website and good reasons for returning to it. Otherwise, they will search for other sources of information to fulfilling their needs and expectations.

Moreover, Transformation is essentially about change, and the basis for digital business transformation is organizational change. Organizational change is where most of the challenges and opportunities reside, associated with individuals, procedures, strategies, structures, and competitive dynamics (Michael Wade, 2015). The understanding of the crucial need for businesses to become digital is the first for businesses to redesign their strategy and culture.

The pace of technology creates greater stress for the presence of movements and transformations of the businesses for new "Blue Oceans". This implies that businesses are transforming their way of doing work, not only in their internal procedures and effectiveness but also in the external interaction with their customers and opportunities. Thus, the push to change may come from emerging technologies that allow for new capacities. If adopted first, and incorporated in new ways, these new technologies could provide points of competitive advantages. Michael Wade (2015) sees that three questions need to be asked by businesses preparing for digital transformation: why do I need to transform? what do I need to transform? and how should I transform? Understanding the need for transformation and having a strong understanding of what needs to change is crucial, but implementation is the key to success. How to transform is where most businesses fail.

As a conclusion, the businesses must get advantages of the UGC with its affiliated eWOM by two different ways; the first one, by the good and continuous monitoring for the online social platforms to be able to handle any negative feedback and to take immediate corrective actions, the second one, by creating his own e-platform as an alternative platform for these public ones, to be under his eye and control for easier data analysis and quicker reaction.

When the companies' managers tend to be aware of what is said online about their business and proactively defend their position or persuade the potential customers by using one or more of the online platforms, this means they started to create a digital customer relation (S. Molinillo et al., 2016).

There are some instances of future technological trends that could be (some are already being deployed) in the tourism industry to facilitate the digital transformation (H. Chesbrough, et al., 2008), such as:

- Virtual Reality (VR) and Augmented Reality (AR) - These technologies will make it possible to alter the whole concept of traditional excursions,

- Internet of Things (IoT) - Will enable tourism establishments to know precisely what is currently happening with their customers in real-time. With this data, they could provide relevant information for those customers online, such as fresh particular promotions or tips to solve certain problems. 
- Semantic Social Networks (SSN) - For instance, imagine a guest who is a fan of a certain hotel Facebook page and when the Bot Agent of that hotel detects that the guest is nearby or already inside, using GPS technology or WIFI range, could immediately start asking him throughout the Facebook Messenger for his reservation details and preferences.

- Really Simple Syndication (RSS) - Enables customers to receive updated content and information by email. Some examples of RSS feeds may include low airline rates or news about tourist destinations that travelers are interested to visit (Ozlem Alikilic, 2018).

Many other trends are being developed to confirm that a digital transformation will underpin evolution. Businesses need only comprehend the trends, maturity, and ability to innovate, learn from other sectors, and join the notion of open innovation

\section{Research Methods}

The deductive approach and quantitative method were adopted where it uses hypotheses to explain the causal relationships among variables of the study according to (Saunders, Lewis, \& Thornhill, 2016). The researchers used two semi-structured questionnaires to measure three main constructs conducted between the 1st of October and the 15th February, 2020. The first questionnaire form was distributed among a sample of 278 out of 1008 tourist companies were selected using a simple random sampling technique(travel agencies) with a response rate of $70 \%$ (195 travel agency).

\section{Data collection}

The first sampling frame for this research is travel agencies in Egypt. A complete list of these agencies is available from the Egyptian travel Agents Association (ETAA). According to them in (2019), there were 1168 category (A) tourist companies in Egypt. They are located in 23 of Egypt's 27 governorates. Totally, this sample frame consists of 1008 tourist companies. For this sample (travel agencies) the simple random sampling technique adopted. It involves selecting the sample at random from the sampling frame using random number tables, a computer random number generator, such as Research Randomizer (2008).

\section{Travel agencies Sample size and technique}

The actual sample size calculated by the following formula by (Thompson, 2012):

Where

$$
n=\frac{N \times p(1-p)}{\left.\left[N-1 \times\left(d^{2} \div z^{2}\right)\right]+p(1-p)\right]}
$$

$\mathrm{N}$

Population size

$\mathrm{Z}$ Standard $\mathrm{Z}=1.96$ ( $\mathrm{z}$ value corresponding to the level of confidence required)

d Error accepted level $=0.05$

$\mathrm{p}$ Probability level $=0.50$

Based on the equation, the suitable sample size is 278 companies, which were randomly selected from the sample frame.

The second sample frame for this research as there is no sampling frame available (tourists/users). Thus, researchers adopted the non-probability sampling technique (self-selection sampling technique) to enable answering these research questions. The self-selection sampling 
technique is adopted according to (Saunders, Lewis, \& Thornhill, 2016) when each case is allowed, usually individuals, to identify their desire to take part in the research. Where researchers publicized the need for cases by asking them to take part or advertising in social media such as (facebook and linkedin) and sending google forms. Also, researchers collect data from those who responded. Cases that self-select often do so because of their strong feelings or opinions about the research question(s) or stated objectives.

This research used an online questionnaire using Google forms https://forms.gle/Uji3cFamKKmos2JcA for travel agencies and https://forms.gle/vFH8yRxuSPGm5VNDA for tourists (users) in addition to face-to-face questionnaires technique for collecting data.

Moreover, According to Hair et al (2014), the minimum sample sizes in SEM based on the model complexity and basic measurement model characteristics is (100) for the Models containing five or fewer constructs, each with more than three items (observed variables) and with high item communalities (.6 or higher).

\section{Questionnaire design}

The semi-structured questionnaires in this research; includes a mixture of closed-ended, openended and partially closed-ended questions to allow the respondents to choose the most relevant answers and add extra information.

\section{Variables of the study}

The main constructs of the study as shown in figure (2) are the User Generated content, intention to purchase, and the digital transformation of travel agencies.

Fig. 1: Research model including the main constructs of the study

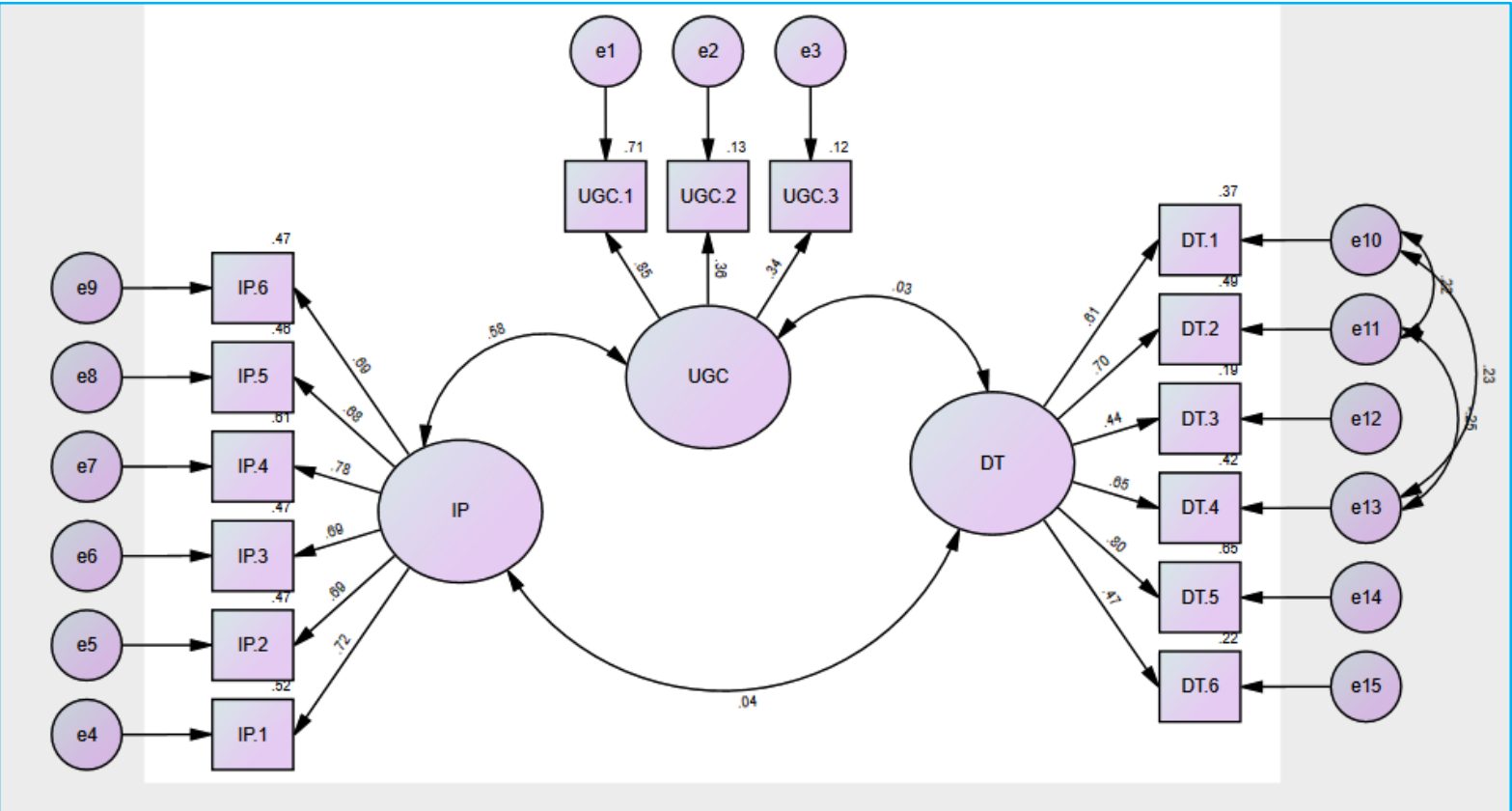

Based on the previous theoretical framework, this research tests the following hypotheses:

H1. The user generated content (UGC) has positive effect on digital transformation (DT) of Travel Agencies in Egypt. (Alternative)

H2. The user generated content (UGC) has negative effect on digital transformation (DT) of Travel Agencies in Egypt. (Null) 
H3. The user generated content (UGC) has a positive effect on customers' intention to purchase (IP). (Alternative)

H4. The user generated content (UGC) has a negative effect on customers' intention to purchase (IP). (Null)

H5. Customers' intention to purchase (IP) has a positive effect on digital transformation (DT) of travel agencies in Egypt. (Alternative)

H6. Customers' intention to purchase (IP) has a negative effect on digital transformation (DT) of travel agencies in Egypt. (Null)

H7. There is a significant correlation between user generated content (UGC) and their intention to purchase (IP). (Alternative)

H8. There is no significant correlation between user generated content (UGC) and their intention to purchase (IP). (Null)

These variables are developed from the literature review and some variables are also replicated from previous studies' questionnaires as the following:

User Generated content (UGC), Intention to purchase (IP), and Digital Transformation of travel agencies (DT) adapted from: (Burgess, Sellitto, Cox, \& Buultjens, 2009, Alcázar, Piñero, and de Maya, 2014, Sethna, Hazary, and Bergiel 2017).

A Five-point Likert scales (1 for strongly disagree to 5 for strongly agree) were used to collect the perceptions of the tourists (users) and travel agencies in Egypt.

\section{Questionnaire layout}

The initial questionnaire forms were designed and then procedures were followed to validate it and ensure that it measures what it was supposed to measure. The final questionnaire forms are divided into Three parts included user generated content (UGC), and Users intention to purchase (IP) in the first form, and digital transformation of travel agencies in the second form with a response for each item ranges from strongly disagree (1) to strongly agree (5).

\section{Selection of Estimation methods}

According to Hair et al (2014) Maximum likelihood estimation (MLE), is more efficient and unbiased when the assumption of multivariate normality is met. Moreover, it is a flexible approach to parameter estimation in which the "most likely" parameter values to achieve the best model fit are found.

\section{Data analysis tools}

Structural equation modeling (SEM) the advanced multivariate technique was used for the quantitative data analysis. With its ability to measure complicated causal relationship among constructs, SEM is considered the highly appropriate analytical approach for this type of study (Olsson et al. 2000). Moreover, Amos software version (26) was used to conduct the structural equation modeling analysis.

It depicts the regression weights of independent variables on dependent ones. In addition, the statistical package for social sciences (SPSS version 22, Chicago, IL) also is used. 


\section{Defining individual constructs/ developing and specifying measurement model:}

Fig. 2: Observed variables (Indicators) specified to latent variables

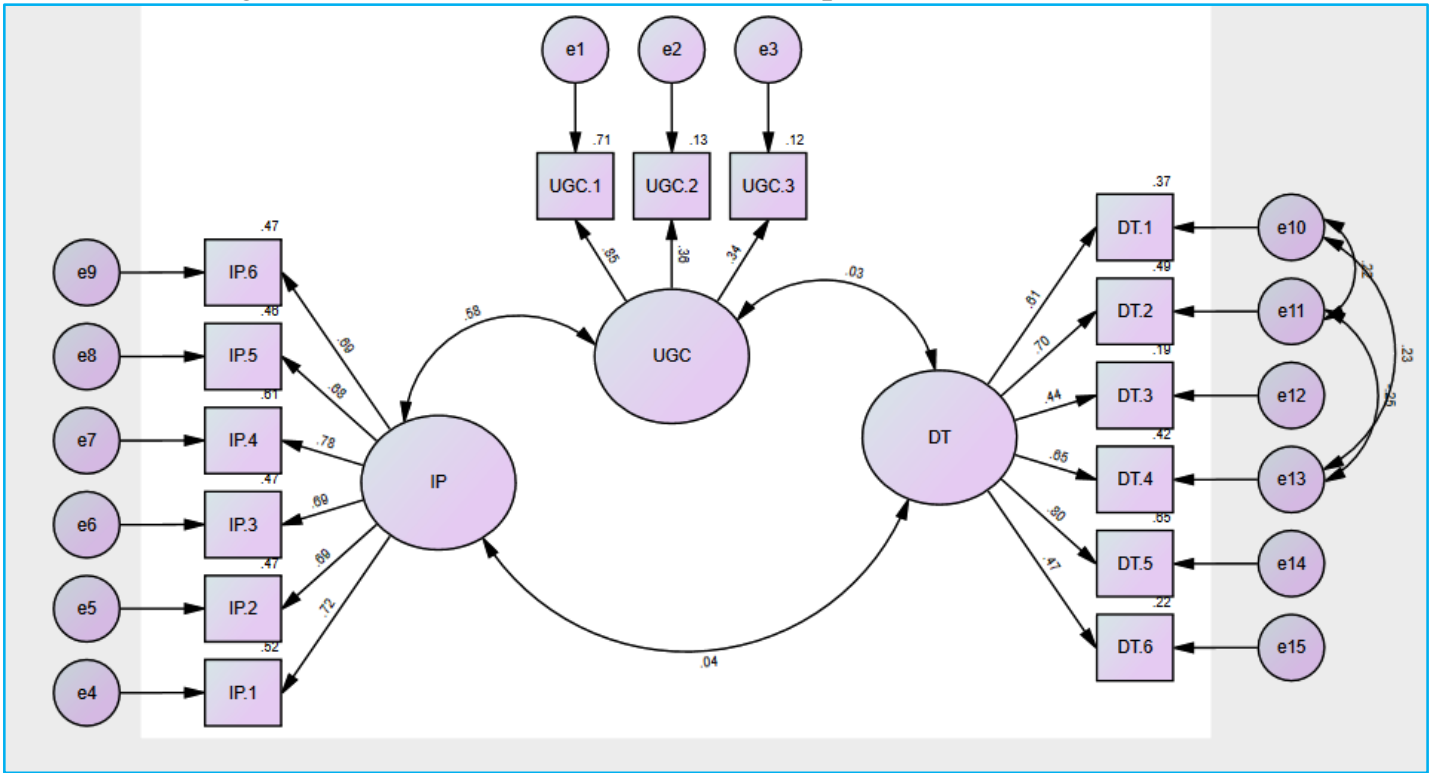

The previous SEM model specifies the indicators for each construct and enables an assessment of construct validity.

\section{Assessing measurement model validity}

According to Hair et al (2014), the measurement model specifies the indicators for each construct and enables an assessment of construct validity.

Construct validity means the extent to which a set of measured variables represent the theoretical latent construct they are designed to measure.

Moreover, it measures the relationships between the observed variables (indicators) and the unobserved variables (constructs) as stated by Van de Wijngaert (2010).

According to Hair et al (2014), measurement model validity depends on establishing acceptable levels of goodness-of-fit for the measurement model and finding specific evidence of construct validity.

The researchers reported at least one incremental index and one absolute index, in addition to the $\chi 2$ value and the associated degrees of freedom.

\subsection{Measurement Model (1) (UGC and DT) levels of goodness-of-fit}

Model fit compares the theory to reality by assessing the similarity of the estimated covariance matrix (theory) to reality (the observed covariance matrix). If a researcher's theory were perfect, the observed and estimated covariance matrices would be the same. 
Fig.3: Measurement Model (1) (UGC and DT)

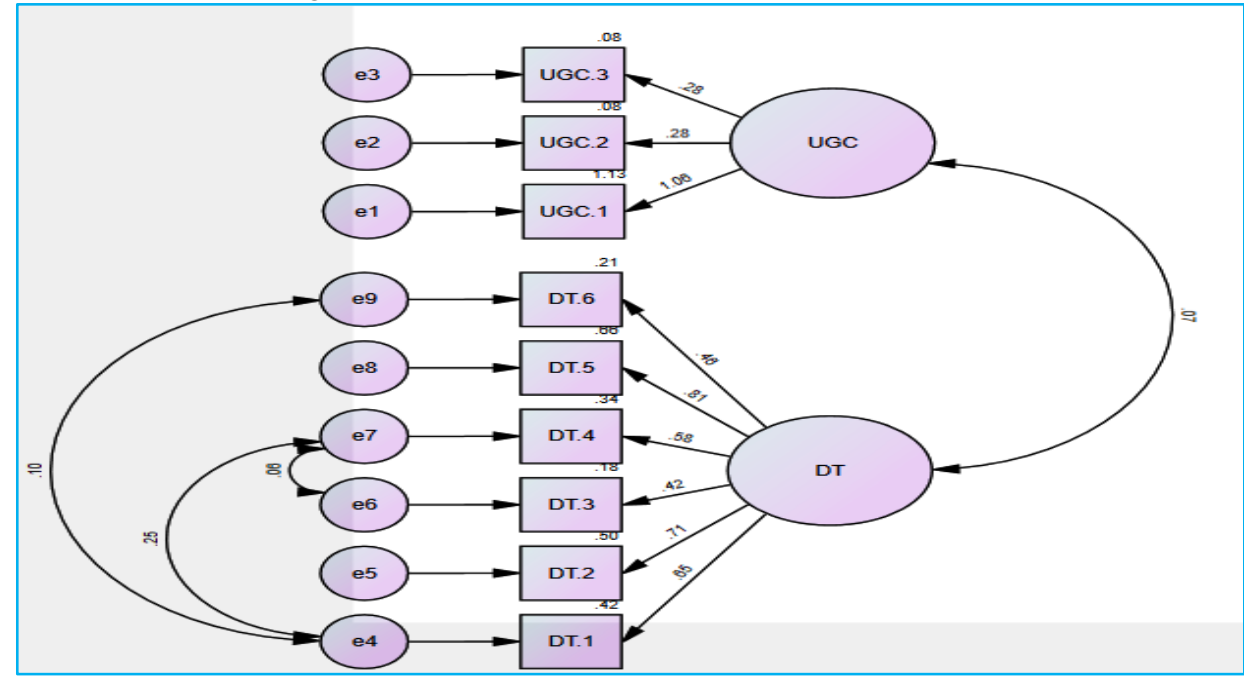

Looking at the results of the measurement model, number of models fit indices should be within target limits as stated by Hair et al (2014). This includes:

- Chi-square $(\chi 2)(\mathrm{GOF})=31.863$ where it is the only statistical test of the difference between matrices in SEM;

- Degrees of freedom $(\mathrm{DF})=23$ (must be $>0$ ) where it represents the amount of mathematical information available to estimate model parameters. The number of degrees of freedom for a SEM model is determined by $\mathrm{df}=1 / 2[(\mathrm{p})(\mathrm{p}+1)]-\mathrm{k}$ where $\mathrm{p}$ is the total number of observed variables and $\mathrm{k}$ is the number of estimated (free) parameters;

- Chi-square probability level $(\mathrm{P}-\mathrm{Value})=0.103$ (ideal when $>.05$ ) where we look for a relatively small Chi-square $\left(\chi^{2}\right)$ value (and corresponding large p-value), indicating no statistically significant difference between the two matrices, to support the idea that a proposed theory fits reality. Relatively small $\chi^{2}$ values support the proposed theoretical model being tested.

\section{Measurement model incremental fit indices}

Incremental fit indices differ from absolute fit indices in that they assess how well the estimated model fits relative to some alternative baseline model. The most common baseline model is referred to as a null model, one that assumes all observed variables are uncorrelated. Also, they are sometimes referred to as comparative fit indices.

- Comparative Fit Index $(\mathrm{CFI})=.949$ (ideal when $>0.9$ ) where it is normed so that values range between 0 and 1, with higher values indicating better fit. Furthermore, CFI values above .90 are usually associated with a model that fits well.

- Root Mean Square Error of Approximation (RMSEA) =0.06 (a cutoff value of .05 or .08) where it represents clearly how well a model fits a population, not just a sample used for estimation. Lower RMSEA values indicate a better fit. Previous research had sometimes pointed to.

- Parsimony Fit Indices: It provides information about which model among a set of competing models is best, considering its fit relative to its complexity. Parsimony Normed Fit Index ratio $(\mathrm{PNFI})=0639$ (highest PNFI values represent good fit) where it is considered the basis for (Parsimony Fit Indices) and is calculated as the ratio of degrees of freedom used by a 
model to the total degrees of freedom available. The values of the PNFI are meant to be used in comparing one model to another with the highest PNFI value being most supported with respect to the criteria captured by this index.

Measurement Model (2) (UGC and IP) levels of goodness-of-fit $\boldsymbol{r}, \boldsymbol{r}$

Fig. 4: Structural model (UGC) and Digital Transformation

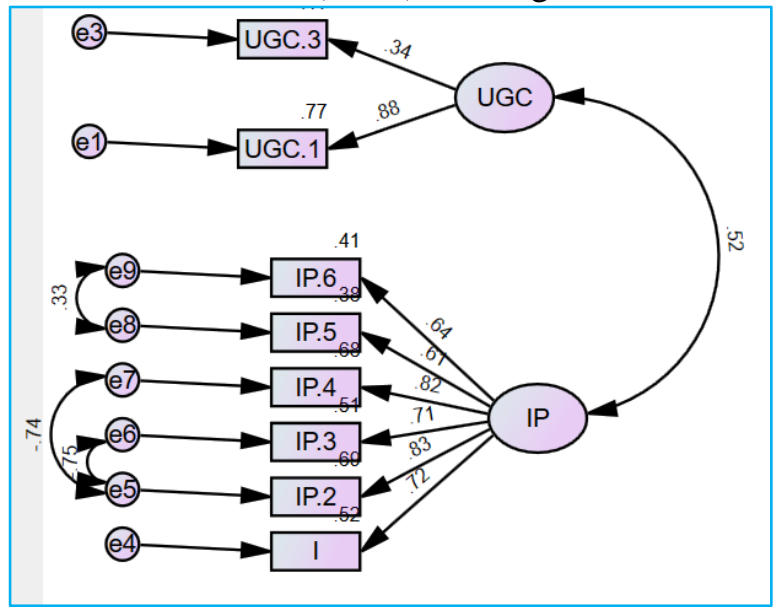

Looking at the results of the measurement model, a number of models fit indices should be within target limits as stated by Hair et al. (2014). This includes:

- Chi-square $(\chi 2)(\mathrm{GOF})=31.719$

- Degrees of freedom $(\mathrm{DF})=16$

- Chi-square probability level $(\mathrm{P}-$ Value $)=0.11$

Measurement model incremental fit indices

- Comparative Fit Index $(\mathrm{CFI})=.946$

- Root Mean Square Error of Approximation (RMSEA) $=.098$

Parsimony Fit Indices: Parsimony Normed Fit Index ratio $(\mathrm{PNFI})=.571$

\subsection{Measurement Model (3) (IP and DT) levels of goodness-of-fit}

Fig. 5: Specifying Structural model Intention to purchase (IP) and Digital Transformation (DT)

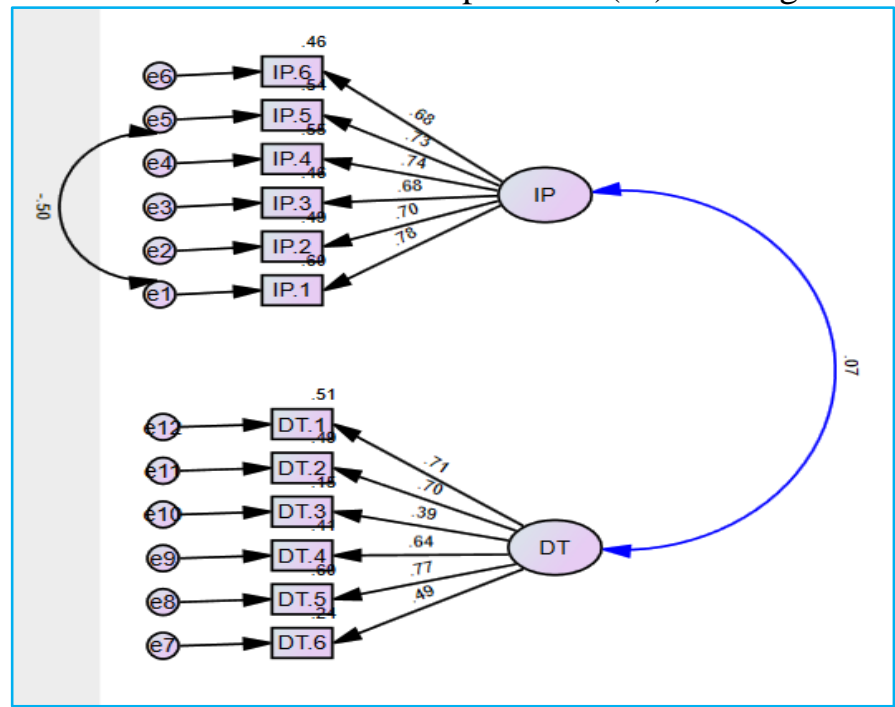


Looking at the results of the measurement model, a number of models fit indices should be within target limits as stated by Hair et al (2014). This includes:

- Chi-square $(\chi 2)(\mathrm{GOF})=70.513$

- Degrees of freedom $(\mathrm{DF})=51$

- Chi-square probability level $(\mathrm{P}-$ Value $)=0.36$

Measurement model incremental fit indices

- Comparative Fit Index (CFI) = .952

- Root Mean Square Error of Approximation (RMSEA) $=.061$

Parsimony Fit Indices: Parsimony Normed Fit Index ratio $(\mathrm{PNFI})=.773$

4.1 Specifying the first structural model (UGC and Digital Transformation

Fig. 6: Specifying Structural model (UGC) and Digital Transformation

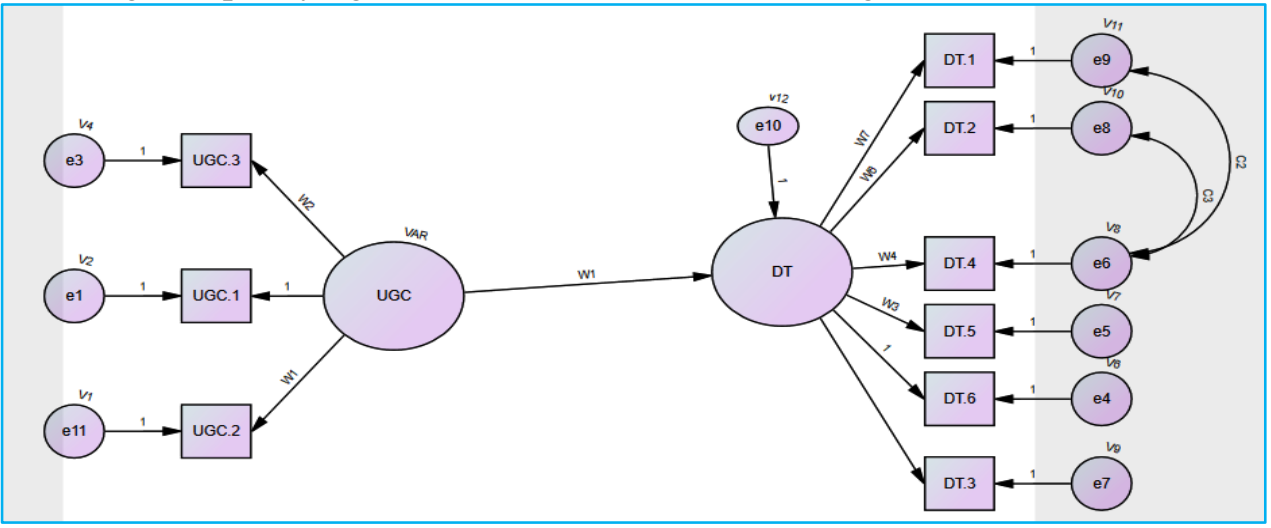

4.2 Specifying structural model (2) (UGC and Intention to Purchase):

Fig. 7: Structural model (UGC) and Intention to purchase (IP)

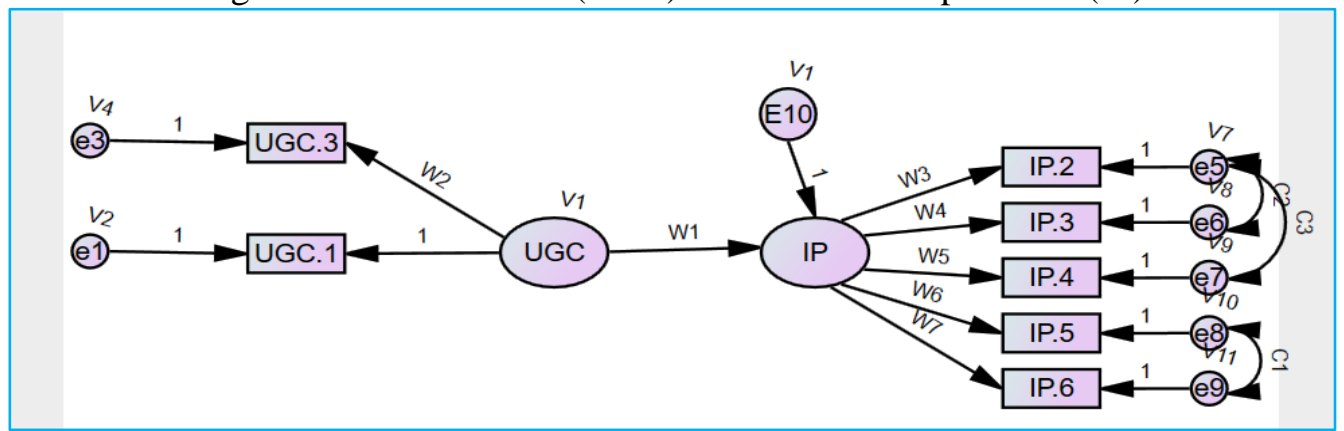

4.3 Specifying structural model (3) (Intention to Purchase (IP) and Digital Transformation (DT)

Fig. 8: Structural model Intention to purchase (IP) and Digital Transformation (DT)

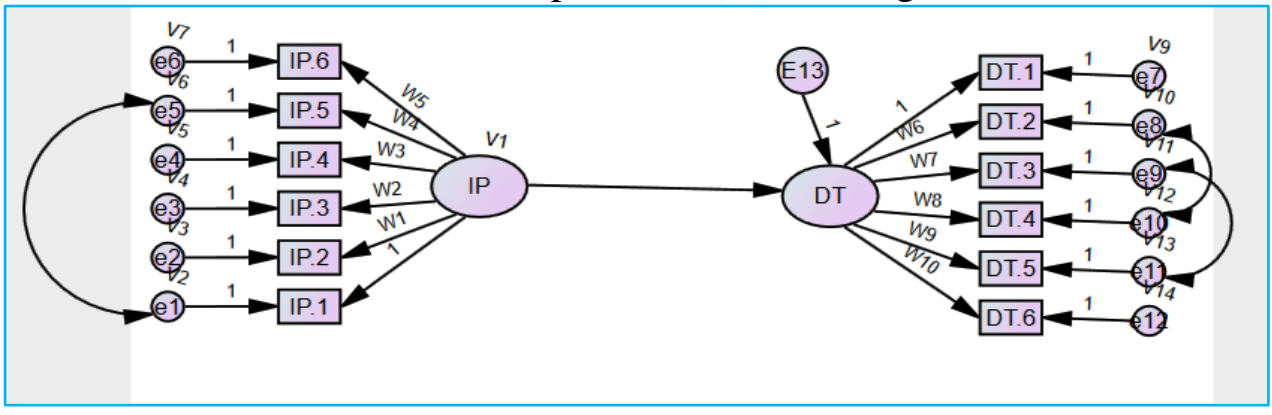




\section{The structural models and Hypotheses-testing results:}

The structured model looks at the causal relationships among the unobserved variables Hox (2010). It depicts the regression weights of independent variables on dependent ones.

\subsection{Structural model (UGC) and Digital Transformation (DT)}

Fig. 9: Structural model (UGC) and Digital Transformation (DT)

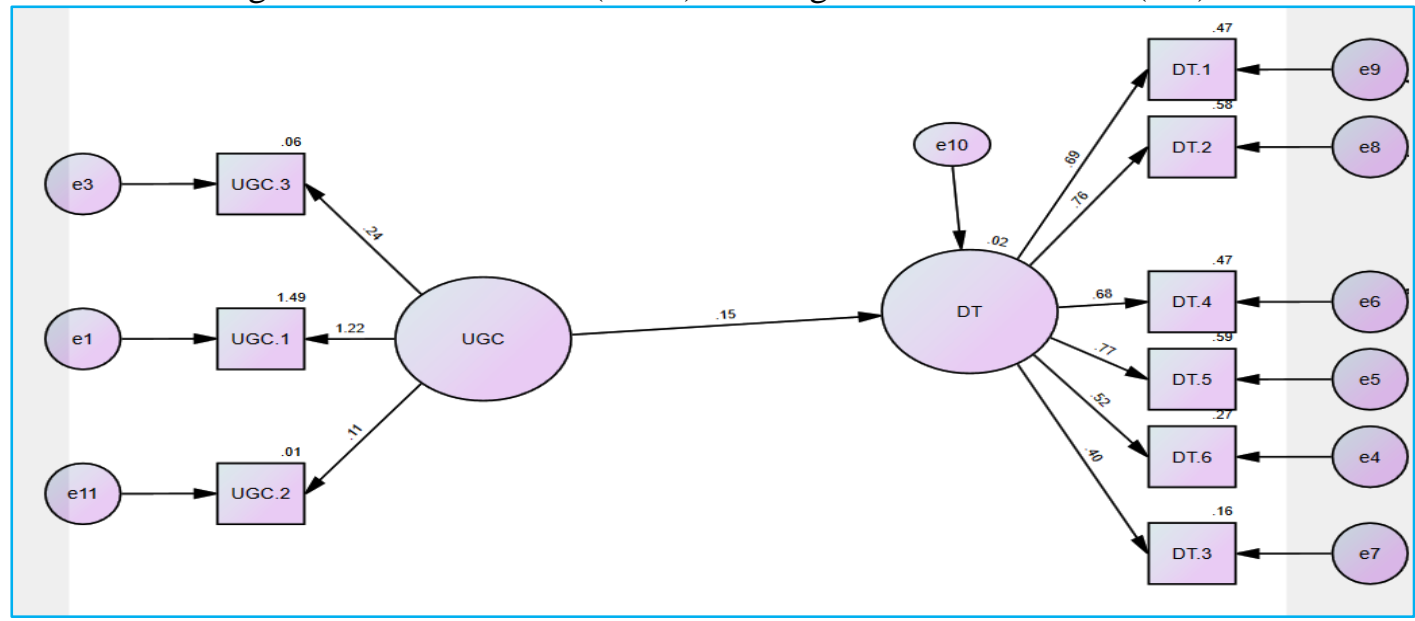

Structural model Goodness of Fit:

- Chi-square $=28.793$

- Degrees of freedom $=26$

- Chi-square P-value $=.321$

Measurement model incremental fit indices:

- Comparative Fit Index CFI = .984

- Root Mean Square Error of Approximation RMSEA= .032

Parsimony Fit Indices: Parsimony Normed Fit Index PNFI Ratio $=.722$

Empirical findings

According to the previous structural model, the following findings proved that user generated content has a weak positive effect on Egyptian Travel agencies' digital transformation where $(\beta=0.15, \mathrm{P}<0.05)$ and interprets only $0.2 \%$ of Egyptian Travel agencies' Digital transformation where $(\mathrm{R} 2=0.02)$. Thus, the alternative hypothesis (h1) is supported and the null hypothesis (h2) is rejected.

\subsection{Structural model (UGC) and Intention to purchase (IP)}

Fig. 10: Structural model (UGC) and Intention to purchase (IP)

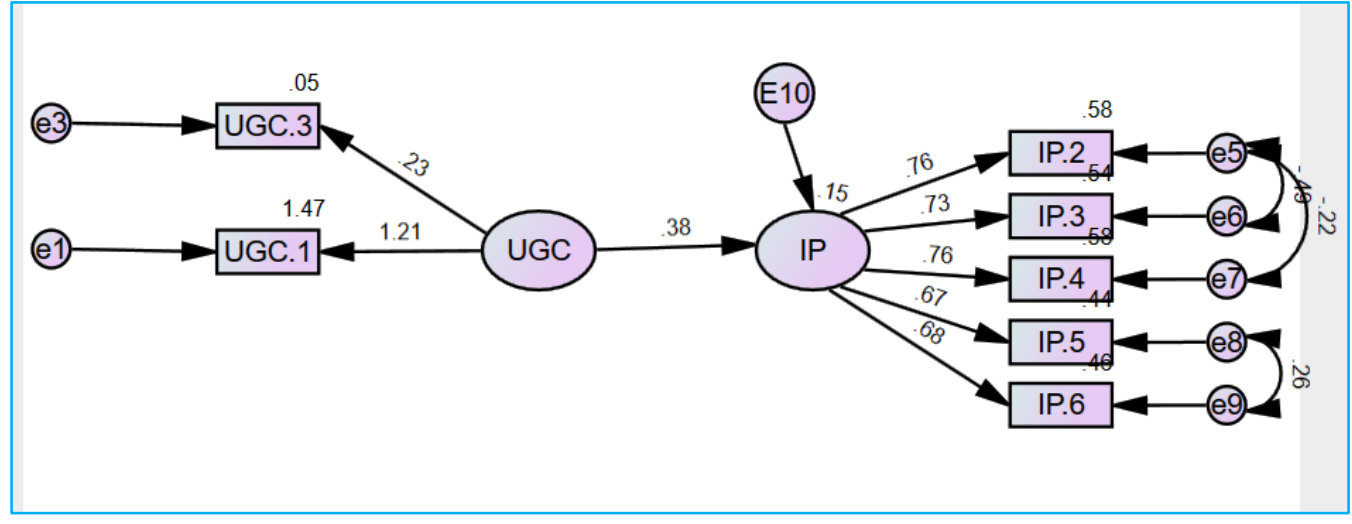


Structural model Goodness of Fit:

- Chi-square $=21.788$

- Degrees of freedom $=11$

- Chi-square P-value $=.026$

Measurement model incremental fit indices

- Comparative Fit Index CFI = .949

- Root Mean Square Error of Approximation RMSEA= .098

Parsimony Fit Indices: Parsimony Normed Fit Index PNFI Ratio $=.524$

Empirical findings

The findings of the previous structural model indicated that user generated content has a positive effect on customers' intention to purchase where $(\beta=0.38, \mathrm{P}<0.05)$ and interprets $15 \%$ of customers' intention to purchase $(\mathrm{R} 2=0.15)$. Consequently, the alternative hypothesis ( $\mathrm{h} 3)$ is supported, and the null hypothesis (h4) is rejected.

\subsection{Structural model Intention to purchase (IP) and Digital Transformation (DT)}

Fig. 11: Structural model Intention to purchase (IP) and Digital Transformation (DT)

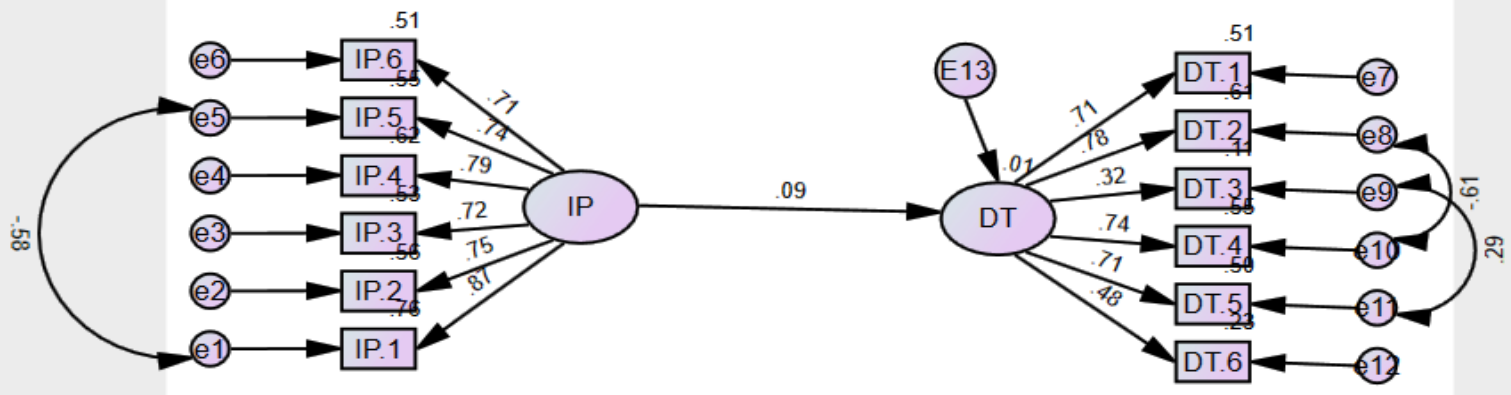

Structural model Goodness of Fit measures:

- Chi-square $=68.515$

- Degrees of freedom $=27$

- Chi-square P-value $=.051$

Measurement model incremental fit indices

- Comparative Fit Index CFI = .957

- Root Mean Square Error of Approximation RMSEA= .058

Parsimony Fit Indices: Parsimony Normed Fit Index PNFI Ratio= .773

Empirical findings

According to the previous structural model, the following findings proved that customers' intention to purchase has a weak positive effect on Egyptian Travel agencies Digital transformation where $(\beta=-0.09, \mathrm{P}<0.05)$ and interprets only $0.1 \%$ of Egyptian Travel agencies' Digital transformation where $(\mathrm{R} 2=0.01)$. Therefore, the alternative hypothesis $(\mathrm{h} 5)$ is supported, whereas the null hypothesis (h6) is rejected. 


\subsection{Correlation between User Generated Content (UGC) and Intention to Purchase (IP)}

Fig. 12: Correlation between Users generated content (UGC) and Intention to purchase (IP)

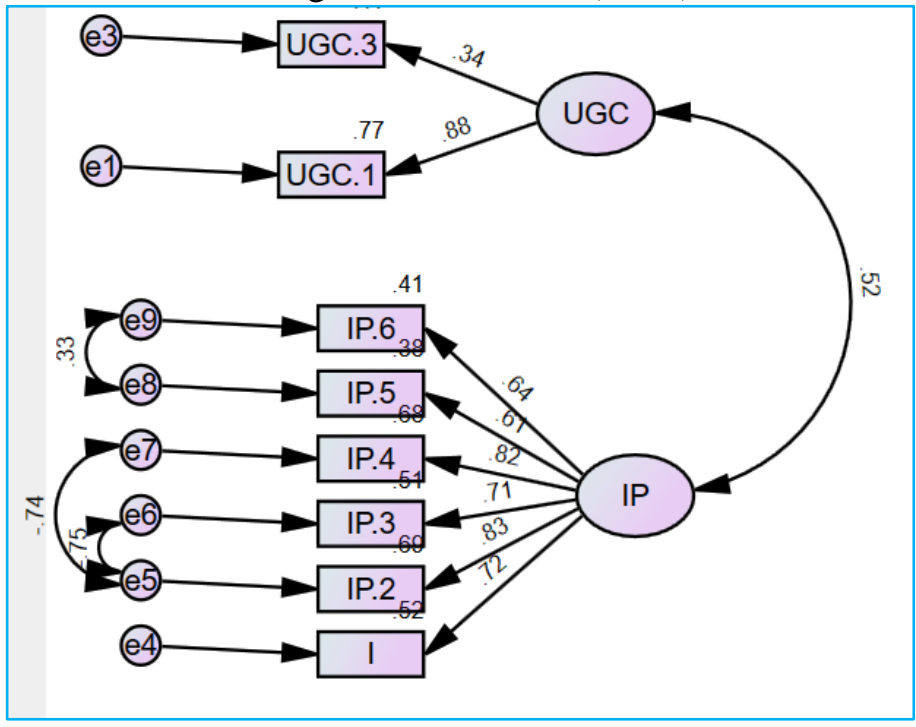

According to the previous measurement model, the findings proved that a significant moderate correlation (covariance) was found between User Generated Content (UGC) and Intention to Purchase (IP) where $r=.52$. Therefore, the alternative hypothesis (h7) is supported, and the Null hypothesis (h8) is rejected.

\section{Conclusion:}

This research proposed model depicts a renewed version of the previously proposed models. A new inspection of the data seems to confirm that the new models better explain user-generated content, intention to purchase and digital transformation of travel agencies in Egypt.

Future research should focus on the limitations and enabling factors of the digital transformation of Egyptian travel agencies.

\section{Recommendations and implications for Egyptian travel agencies:}

Firstly, the Egyptian travel agencies seeking to get benefit from user-generated content to maintain and increase their market share must be aware of the following:

- Travel agencies that stand to benefit from online user-generated content have to recognize that positive UGC is a direct result of offering excellent service and experience that customers want to tell everybody about it.

- Failure to provide travel services that make things as easy as possible for your customers, could result them making use of various channels to recommend people stay away from your business.

- Travel agencies must follow blogs, forums, and social media to find out the level of service that their clients expect.

- Travel agencies must stimulate and provide space to their customers' feedback from any channel, and get the benefit of it to develop their services and products.

- Travel agencies must promptly respond to any complaints or negative UGC related to its provided services.

- Travel agents must dedicate more resources for customer service to maintain their online reputation, even if they offer predominantly offline services. 
Secondly, as for the digital transformation, the Egyptian travel agencies must find answers for a critical three questions to prepare themselves for digital transformation:

- Why do they need to transform? (The motivation and pushing factors):

- To answer this question, gap analysis needs to take place to help travel agencies to identify the relevant gaps need to be filled, and the extent to which these gaps may negatively impact the business in case it remains unsolved.

- What do they need to transform? (The tools and capacities):

- Digital literacy training programs for travel agencies workforce must be an essential part of any initiative for Digital Transformation. In addition, high-quality PCs and electronic devices need to be available to facilitate the daily operations of the business.

- UGC generate a large volume of unstructured information that travel agencies should own the capacity to ideally analyze in real-time mode to understand what are the needs and experiences that their potential customers are looking for, and adapting their activities, business models, and marketing strategies to those fits.

- Travel agencies must give their customers good reasons for visiting their website and good reasons for returning to it (provide high quality website). Otherwise, customers will search for other sources of information to fulfilling their needs and expectations. Highquality websites have some features such as;

$\checkmark$ Quality content: where the content is original, purposeful, and correctly optimized information which drives people and search engines to read, view, and share.

$\checkmark$ Content length: Usually, the top-ranking websites have more than 900 words of content per page.

$\checkmark$ Images \& Video: The top-ranking web pages have an average of 7 images. The recommended image size is at least $32 \times 32 \mathrm{px}$.

$\checkmark$ Formatting: Web-visitors are less likely to read a poorly formatted post. Google can detect page layout, and poor formatting may lead to penalization.

$\checkmark$ Social media shares: High-quality websites have on-page social media buttons and more social media shares correlate with higher search engine ranking.

$\checkmark$ Mobile-Friendly: Everything a business is doing digitally today ought to be mobile friendly. Majority of online users today use their mobile phones to access the internet.

$\checkmark$ Furthermore, all services should be clearly listed along with the relevant information. The website must be designed in such a way as to allow the users to make a purchase without the need for any assistance. It must be regularly updated keeping in mind the changing needs and preferences of the customers.

\section{- How should they transform? (the procedures and mechanisms):}

- To conduct Digital Transformation effectively in any enterprise or company, each of the five Change Blocks of Digital Transformation must be recognized, discussed and accepted throughout the process and beyond (Niall McKeown, 2017).

$\checkmark$ Strategy \& Culture: Strategy is the starting point for the creation of a highperformance digital business. Without a strategy, the business culture becomes a reactive one, rather than a proactive one, leading to digital services rather than a total digital transformation.

$\checkmark$ Staff \& Customer Engagement: Change is often met with resistance that can come either from employees or customers. Through better communication, the business 
can overcome this resistance by offering clarification about the reasons for change, how it will happen and the expected role of each party.

$\checkmark$ Process \& Innovation: Defining and optimizing processes gives businesses a chance to become more productive and creative.

$\checkmark$ Technology: Transformation should not start with a focus on technology, it should be understood that it is not technology that creates a competitive advantage, but leaders and the strategies that they are developing while using the technology.

Data \& Analytics: A vital component in becoming a high-performance Digital Business is being able to make use of the huge amounts of data and analytics available in the digital age for decision making, innovation and development. Without this capacity, companies will find themselves in stagnation.

\section{References}

Ahuja, RD, Michels, TA, Walker, MM and Weissbuch, M. (2007), Teen perceptions of disclosure in buzz marketing, Journal of Consumer Marketing, 24 (3), 151-159.

Albăstroiu, I. \& Felea, M. (2014) The Implications of User-Generated Content Websites for Tourism Marketing, International Journal of Economic Practices and Theories, 4(2), 222229.

Alcázar, H., Piñero, S., \& De Maya, R. (2014), The effect of user-generated content on tourist behavior: the mediating role of destination image, Tourism \& Management Studies, 10 (Special Issue), 158-164.

Alikilic; Ö. (2018) User Generated Content in Tourism Marketing. Journal of Yasar University, 3(9), 1061-1080.

Anthony, S.D., Viguerie, S.P., Schwartz, E.I., Landeghem, J.V. (2018), Corporate Longevity Forecast: Creative Destruction is Accelerating, Innosight.

Arora, S. (2019), Customer Behaviour-Online Travel Industry in India, SocioEconomic Challenges, 3(1), 2520-6214.

Blackshaw, P., \& Nazzaro, M. (2006), Consumer-generated Media (CGM). Word-of-Mouth in The Age of the Web-fortified Consumer, New York: Nielsen Buzz Metrics.

Bray, J. \& Schetzina, C. (2006), Travel 2.0: Harnessing the Power of User-Generated Content and Tagging. Hospitality Upgrade, Fall, 28-29.

Bruyn, A. \& Lilien, G. (2008), A multi-stage model of world-of-mouth influence, International Journal of Research in Marketing, 25, 151-163.

Buhalis, D. (1998), Strategic Use of Information Technologies in the Tourism Industry, Tourism Management, 19(5); 409-421.

Burgess, S, Sellitto, S, Cox, C \& Buultjens, J (2009), User-generated content (UGC) in tourism: benefits and concerns of online consumers. Australian Regional Tourism Research Centre, Australia.

Hidalgo C. A., Sicilia Piñero M., Ruiz de Maya S. (2014), The effect of user-generated content on tourist behavior: the mediating role of destination image, Tourism \& Management Studies, 10, 158-164.

Chatterjee, P. (2001), Online Reviews: Do Customers Use Them? ACR 2001 Proceedings, eds. M.C. Gilly \& J. Myers-Levy, Association for Consumer Research, 129-134.

Chesbrough, H., Vanhaverbeke, W. and West, J., eds. (2008), Open Innovation: Researching a New Paradigm, $1^{\text {st }}$ edition. Oxford: Oxford University Press.

Court, D., Perrey, J., McGuire, T., Gordon, J., Spillecke, D. (2015), Big Data, Analytics, and the Future of Marketing \& Sales, McKinsey. 
Dessart, L., Veloutsou, C. \& Morgan-Thomas, A. (2015) Consumer engagement in online brand communities: a social media perspective, Journal of Product \& Brand Management, 24 (1), $28-42$.

Dredge, D., Phi, G., Mahadevan, R., Meehan, E. \& Popescu, E.S. (2018) Digitalization in Tourism: In-depth analysis of challenges and opportunities. Low Value procedure GROSME-17-C-091-A for Executive Agency for Small and Medium-sized Enterprises (EASME) Virtual Tourism Observatory, Aalborg University, Copenhagen.

Fatantia, M. N. \& Suyadnya, I. W. (2015) Beyond User Gaze: How Instagram Creates Tourism Destination Brand? Social and Behavioral Sciences 211, 1089 - 1095.

Fernando, A. (2007), Social media change the rules: Say farewell to top-down and hello to consumer-led communication, Communication World, 24 (1), 9-10.

Fitzgerald, M. et al. (2013), Digital Technology Engagement: A New Strategic Imperative, Review of the MIT Sloan M management.

Gelter, H. (2017), Digital tourism - An analysis of digital trends in tourism and customer digital mobile behaviour, Visit Arctic Europe project, Interreg Nord.

Ghose, A. \& Ipeirotis, P.G. (2011), Estimating the helpfulness and economic impact of product reviews: mining text and reviewer characteristics. IEEE Transactions on Knowledge and Data Engineering, 23, (10), 1498-1512.

Gimpel, H. \& Röglinger, M. (2015), Digital Transformation: Changes and Chances - Insights based on an Empirical Study, Project Group Business and Information Systems Engineering (BISE) of the Fraunhofer Institute for Applied Information Technology FIT, Augsburg/Bayreuth.

Hair, J., Barry, W., and Anderson, B., (2014), Multivariate Data Analysis, $7^{\text {th }}$ edition, Pearson new international edition. UK.

Hashim, M. (2016), Art of Digital Jujutsu, Dell EMC World.

Hazari, S., Bergiel, B. and Sethna, B. (2016), Hedonic and utilitarian use of user generated content on online shopping websites, Journal of Marketing Communications, http://10.1080/13527266.2016.1143383.

Hollebeek, L. \& Chen, T. (2014), Exploring positively-versus negatively-valenced brand engagement: a conceptual model, Journal of Product \& Brand Management, Vol. 23, (1), $62-74$.

Hussam Al Halbusi \& Shehnaz Tehseen. (2018) The Effect of Electronic Word-Of-Mouth (EWOM) on Brand Image and Purchase Intention: A Conceptual Paper, SocioEconomic Challenges, 2(3), 83-94.

Ismail, M. H., Khater, M., Zaki, M. (2017), Digital Business Transformation and Strategy: What Do We Know So Far? Cambridge Service Alliance, University of Cambridge.

Jansen van Rensburg, M. (2014), Relevance of travel agencies in the digital age, African Journal of Hospitality, Tourism and Leisure, 3(1), 1-9.

Kane, G.C. et al. (2015), Strategy, Drives Digital Transformation, Not Technology. Review.

Kasturi, V. (2018), Digital speed: 5 strategies to rapidly deliver business value from digital transformation, CIO.

Kaufman, I. \& Horton, C. (2015), Digital Transformation: Using Core Values for Digital Technology to achieve sustainable business objectives, The European Review of Finance.

Kock, N. (2015), WarpPLS 5.0 user manual, Script Warp Systems, Laredo, Texas.

Litvin, S.W., Goldsmith, R.E. and Pan, B. (2008), Electronic word-of-mouth in hospitality and tourism management, Tourism Management, 29, 458-468. 
Kreider, A. (2018), The Top 5 Barriers to Digital Transformation. InTheChat Communications, Whitepaper.

Manap, K. \& Adzharudin, N. (2013), The Role of User Generated Content (UGC) in Social Media for Tourism Sector, WEI International Academic Conference, Istanbul, Turkey.

Michalić, T., Praničević, D.G., Arnerić, J. (2015), The Changing Role of ICT Competitiveness: the case of the Slovenian hotel sector, Economic Research-Ekonomska Istraživanja, 28(1), 367-383.

Molinillo, S., Ximénez-De-Sandoval, J.-L., Fernández-Morales, A., and Coca-Stefaniak, A. (2016), Hotel assessment through social media: The case of TripAdvisor, Tourism \& Management Studies. 12, 15-24.

Munar, A.-M., (2010), Technological mediation and user created content in tourism, CIBEM Working Paper Series, Copenhagen Business School, April.

Nevmerzhitskaya, J. (2013) Scenarios of the future work of business travel agencies. Master's Thesis, Haaga-Helia University of Applied Sciences, Helsinki, Finland.

Olsson, U. H., Foss T., Troye S.V., \& Howell R. D. (2000), The Performance of ML, GLS, and WLS Estimation in Structural Equation Modeling Under Conditions of Misspecification and Nonnormality, Structural Equation Modeling: A Multidisciplinary Journal, 7(4), 557-595.

Park, D., Lee, J., \& Han, I. (2007), The Effect of On-Line Consumer Reviews on Consumer Purchase Intention: The Moderating Role of Involvement, International Journal of Electronic Commerce, 11(4), 125-148.

Panagiota, C. (2017), Digital Transformation in tourism sector, Master's thesis, School of Science \& Technology, Thessaloniki, Greece.

Ribeiro, R. \& Florentino, T. (2016), Digital Transformation in Tourism: a high level analysis of the impact that social networks and mass collaboration concept is having at tourism service providers. The $7^{\text {th }}$ International Conference on Cinema and Tourism - ICCT, Oct 2016.

Ribeiro, R. (2019), Digital Transformation of the Enterprise Value Chains. Global Forum of Intellectual Capital, Lisbon.

Saunders, M., Lewis, P., \& Thornhill, A. (2016), Research methods for business students, Financial Times Prentice Hal, London.

Schuchmann, D. \& Seufert, S. (2015) Corporate Learning in Times of Digital Transformation: A Conceptual Framework and Service Portfolio for the Learning Function in Banking Organisations, iJAC, 8(1), 31-40.

Sebastian, I.M. et al. (2017), How Big Old Companies Navigate Digital Transformation, MIS Quarterly Executive, 16(3), 197-213.

Senecal, S. \& Nantel, J. (2004), The influence of online product recommendations on consumers' online choices, Journal of Retailing, 80(2), 159-69.

Sethna, B., Hazary, S. and Bergiel, B. (2017), Influence of user generated content in online shopping: impact of gender on purchase behavior, trust, and intention to purchase, Int. J. Electronic Marketing and Retailing, Vol. 8(4). 344-371.

Sigala, M. Christou, E. and Gretzel. U. (2012), Social Media in Travel, Tourism and Hospitality: Theory, Practice and Cases, Ashgate Publishing, Ltd.

Smith, D., Menon, S. and Sivakumar, K. (2005), Online peer and editorial recommendations, trust, and choice in virtual markets. Journal of Interactive Marketing, 19(3), 15-37.

Sparks, B. A., Buckley, R., and Perkins, H. E. (2013), Online travel reviews as persuasive communication: The effects of content type, source, and certification logos on consumer behavior. Tourism Management, 39, 1-9. 
Thompson, S. (2012), Sampling, ( $3^{\text {rd }}$ ed.), Wiley series in probability and statistics, http://eu.wiley.com/WileyCDA/WileyTitle/productCd-0470402318.html\#

Van de Wijngaert, L., (2010), A multi-theory approach towards the adoption, use and effects of IT services: The case channel choice in an e-Government setting, Proceedings to the Professional Communication Conference (IPCC), IEEE International, Enschede, Netherlands, http://ieeexplore.iee.. rg/stamp/stamp.jsp?tp=\&arnumber=5529818.

Von Leipzig, T., et al. (2017). Initializing customer-orientated digital transformation in enterprises. Procedia Manufacturing, 8, 517-524.

Wade, M. (2015), Digital Business Transformation: A Conceptual Framework, Global Center for Digital Business Transformation.

World Economic Forum (2017), Digital Transformation Initiative: Aviation, Travel and Tourism Industry. White Paper, January.

Yoo, K.-H. \& Gretzel, U. (2011), Influence of personality on travel-related consumer-generated media creation. Comput. Hum. Behav., 27, (2), 609-621.

Khan. Y., \& Hossain, A. (2018), The Effects of ICT Application on the Tourism and Hospitality Industries in London. SocioEconomic Challenges, 2, (4), 60-68.

Webliography

http://www.iata.org/whatwedo/stb/Documents/StB-White-Paper-2017.pdf

[Accessed: 09/07/2019]

http://innovation.unwto.org/content/digital-transformation [Accessed: 01/09/2019]

https://www.internetworldstats.com/stats.htm [Accessed: 29/03/2019]

https://www.worldbank.org/en/news/feature/2018/09/25/digital-platforms-and-the-future-of-

tourism-a-world-tourism-celebration [Accessed: 05/08/2019] 